EPJ Web of Conferences 82, 01053 (2015)

DOI: $10.1051 /$ epjconf/20158201053

(C) Owned by the authors, published by EDP Sciences, 2015

\title{
Investigation of drop dynamic contact angle on copper surface
}

\author{
Evgenija Orlova ${ }^{a}$, Dmitriy Feoktistov and Geniy Kuznetsov
}

Department of Theoretical and Industrial Heat Systems Engineering, Institute of Power Engineering, Tomsk Polytechnic University, 634050 Tomsk, Russia

\begin{abstract}
This paper presents experimental results of the studying the effect of surface roughness, microstructure and flow rate on the dynamic contact angle at spreading of distilled non deaerate water drop on a solid horizontal substrates. Copper substrates with different roughness have been investigated. For each substrate static contact angles depending on volume flow rate have been obtained using shadow system. Increasing the volume flow rate resulted in an increase of the static contact angle. It was found that with increasing surface roughness dynamic contact angle arises. Also difference in formation of the equilibrium contact angle at low and high rates of drop growth has been detected.
\end{abstract}

\section{Introduction}

There is a lack in understanding nature of three phase contact line at the dynamic interaction of a drop with a solid surface. It leads to inhibition of technology development at cooling surfaces [1], various coatings [2], ink jet printing [3,4], spraying fuel in internal combustion engines [5] and etc.

Development of studying hydrodynamics of gas-liquid flows in microsystems and micro-channels is determined by need to reduce the characteristic sizes of the devices in various engineering fields, such as in energy and medicine, aerospace industry and electronics [6]. Processes occurring in such flows are characterized by the following factors: thermal properties of liquid, a specific coolant flow, surface micro relief and surface wettability.

Despite the large number of researchers (T. Jung, P.S. Laplace, P.A. Rebinder, B.V. Derjagin, R. Hoffman, J. Batchelor, O.V. Voinov, T. Blake) engaged in the study of wetting and spreading of liquids on a solid surface, for today fundamental principles of the theory of three-phase contact line properties haven't been developed yet. There is a lack of studying systems with a large range of variation of the contact line spreading rate and the wetted surface roughness in the scientific literature. The purpose of the work is investigation of effect of surface roughness, microstructure and flow rate on the dynamic contact angle (DCA) at spreading of distilled non deaerate water drop on a solid horizontal substrate.

\footnotetext{
${ }^{a}$ Corresponding author: enja199105@gmail.com
}

This is an Open Access article distributed under the terms of the Creative Commons Attribution License 4.0, which permits unrestricted use, distribution, and reproduction in any medium, provided the original work is properly cited. 


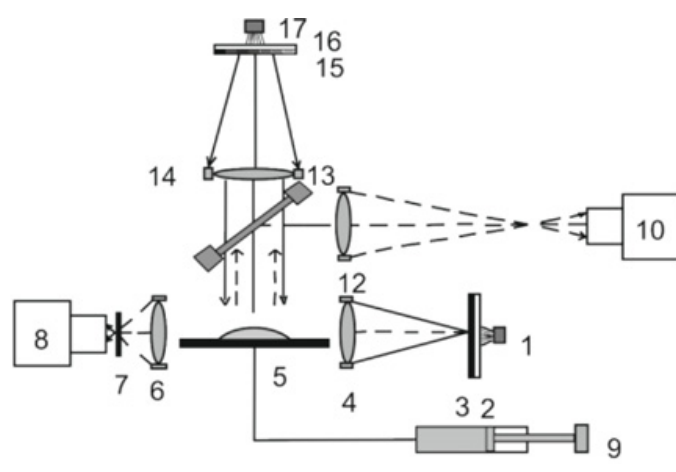

(a)

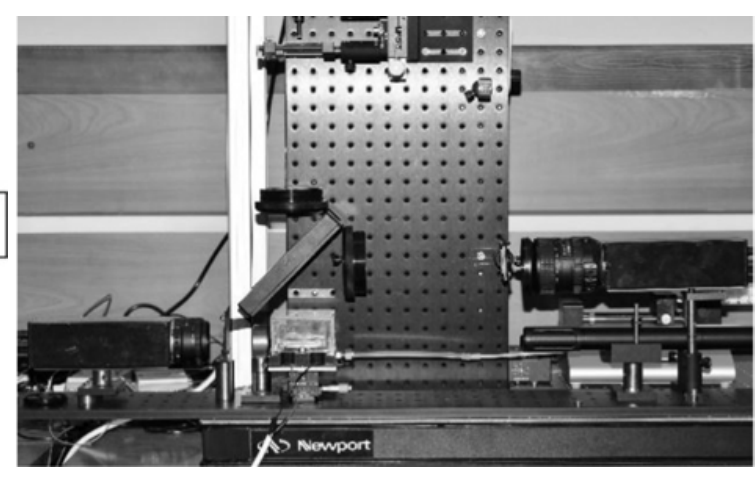

(b)

Figure 1. Schematic diagram (a) and general view (b) of the experimental setup: 1, 17 - light source; 2, 16 - ground glass; 3 - hole; 4, 14 - collimating lens; 5 - substrate; 6 - condensing lens; 7, 11 - transparent shield with a hole; 9 - syringe pump; 8, 10 - high-speed video camera; 12 - Schlieren lens; 13 - beam splitter; 15 - coding filter.

\section{Research technique}

The researches have been conducted using experimental setup shown in Fig. 1. It consists of shadow and Schlieren systems. Video recording of drop spreading process is conducted simultaneously on both sides. Camera of Schlieren system is used to control the axial symmetry of the drop. The concept of research and operation are given in [7]. We used copper substrates as a solid surface. Each substrate is a disk with diameter of $54 \mathrm{~mm}$ and thickness of $4 \mathrm{~mm}$.

The substrates with different surface micro relief were chosen to assess the effect of roughness and surface profile on the wetting characteristics during drop spreading. Rough surfaces are obtained by bombarding a smooth copper surface with $\mathrm{Al}_{2} \mathrm{O}_{3}$ sizes of 10 and 100 microns.

Each substrate has the opening in the middle with diameter of $2 \mathrm{~mm}$. Droplet with volume of $0.3 \mathrm{ml}$ is squeezed through this opening with the help of syringe pump (Cole-Parmer Touch Screen). Volume flow rate was changed from $0.005 \mathrm{ml} / \mathrm{sec}$ to $0.16 \mathrm{ml} / \mathrm{sec}$. Thus, measuring dynamic contact angles was held by "sitting drop" method.

Drop spreading was recorded by high-speed cameras FastCAMSA1.1 model 675K-M1. Recording speed varies from 10 to 1281 frames/sec depending on the flow rate of the wetting liquid.

The snapshots obtained during the experiment were processed by KRUSS program which used the Young-Laplace method [8] to determine the DCA. This program software recognizes the drop profile and determines its geometrical parameters, such as contact angle (on the left and on the right side, mid value), base diameter, height, volume, surface area, etc. Drop profile with the main geometrical parameters is presented in Fig. 2.

\section{Results and discussion}

According to results of the preliminary experiment the values of influencing factors were defined (Table 1). Also the substrate profile was studied using surface analyzer "Micro Measure 3D station" for defining arithmetic average roughness $(\mathrm{Ra})$.

For understanding spreading of liquid on the surface it is necessary to know the value of the static contact angle on the surface. Table 2 shows experimental data of the static contact angles on the studied substrates depending on the volume flow rate of distilled water drop formation. Static contact angles were measured at a constant wetted area. 


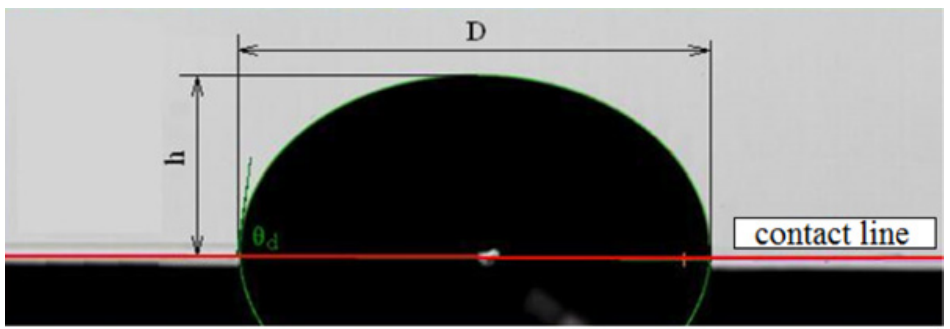

Figure 2. Geometrical parameters of the drop.

Table 1. The main influencing factors.

\begin{tabular}{|l|l|}
\hline Drop volume & $0.3 \mathrm{ml}$ \\
\hline Flow rate of distilled water & $0.005 ; 0.01 ; 0.02 ; 0.04 ; 0.08 ; 0.16 \mathrm{ml} / \mathrm{sec}$ \\
\hline Substrate material & Copper \\
\hline Roughness parameter of surface Ra & $\begin{array}{l}\text { Flexible copper - Ra } 0.591 \mu \mathrm{m} ; \\
\text { copper - Ra } 5,190 \mu \mathrm{m} ; \\
\text { copper - Ra } 6,210 \mu \mathrm{m} ;\end{array}$ \\
\hline Wetting liquid & non deaerate distilled water \\
\hline
\end{tabular}

Table 2. Static contact angles.

\begin{tabular}{|l|l|l|l|l|l|l|}
\hline Substrate & \multicolumn{5}{|c|}{ Flow rate of distilled water, ml/sec } \\
\hline & 0.005 & 0.01 & 0.02 & 0.04 & 0.08 & 0.16 \\
\hline Copper I $(\operatorname{Ra} 0.592 \mu \mathrm{m})$ & $76^{\circ}$ & $86^{\circ}$ & $64^{\circ}$ & $75^{\circ}$ & $79^{\circ}$ & $80^{\circ}$ \\
\hline Copper II $(\operatorname{Ra~} 5.190 \mu \mathrm{m})$ & $64^{\circ}$ & $65^{\circ}$ & $65^{\circ}$ & $66^{\circ}$ & $78^{\circ}$ & 83 \\
\hline Copper III $(\operatorname{Ra} 6.210 \mu \mathrm{m})$ & $60^{\circ}$ & $62^{\circ}$ & $66^{\circ}$ & $67^{\circ}$ & $77^{\circ}$ & 85 \\
\hline
\end{tabular}

It was found that all substrates are characterized by certain static contact angles, which depend on the volume flow rate of drop formation. Increasing the volume flow rate resulted in an increase of the static contact angle. The maximum difference in static contact angles $\left(22^{\circ}\right)$ on the substrate is found on copper III ( $\operatorname{Ra} 6.210 \mu \mathrm{m})$.

According obtained experimental data the contact line velocity was calculated. This parameter describes the rate of spreading droplets on a surface and is determined from the equation:

$$
V k=\frac{C \cdot\left(B_{d 3}-B_{d 1}\right)}{2 \cdot\left(K_{3}-K_{1}\right)},
$$

where $\mathrm{C}$ - frame capture speed, frame/sec; $\mathrm{B}_{d 1}, \mathrm{~B}_{d 3}$ - droplet diameter in the previous and the next moment, respectively, $\mathrm{mm} ; \mathrm{K}_{1}, \mathrm{~K}_{3}$ - number of the frame at previous and the next moment in time, respectively, frame.

During the process of drop spreading on copper surfaces increasing the surface roughness from $0.591 \mu \mathrm{m}$ to $5.190 \mu \mathrm{m}$ led to an increase of the maximum value of the advancing DCA. But the subsequent increase of roughness to $6.210 \mu \mathrm{m}$ did not cause a further increase of the DCA. Maximum value of the contact angle $\left(112^{\circ}\right)$ was recorded at volume flow rate of distilled water of $0.160 \mathrm{ml} / \mathrm{sec}$ on copper II (Ra $5.190 \mu \mathrm{m})$ (Fig. 3b) with the contact line velocity of 4,250 mm/sec. Also maximal contact angle $\left(112^{\circ}\right)$ was obtained on copper III $(\mathrm{Ra} 6.210 \mu \mathrm{m})$ in the contact line velocity range of $2.430-3.480 \mathrm{~mm} / \mathrm{sec}$. In this case we can observe divergence of the experimental results with theoretical studies [9], according to which the growth of the contact angles with increasing roughness is noted on hydrophobic surfaces $\left(\theta>90^{\circ}\right)$, whereas the copper surfaces are initially hydrophilic $\left(\theta<90^{\circ}\right)$ (Table 2). It can be explained by the fact that the contact angles affect not only surface roughness (which characterized by roughness coefficient $\mathrm{k}$ ) but also shape and arrangement of microgrooves and micro 


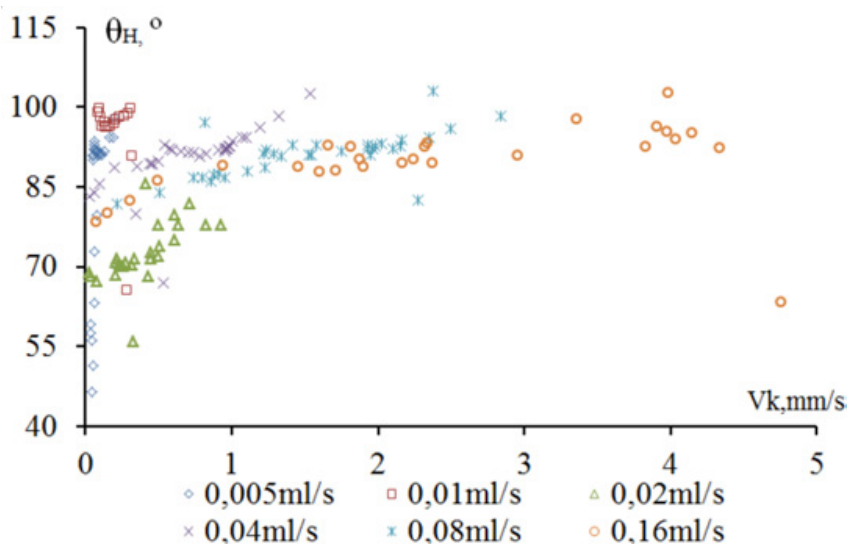

(a)

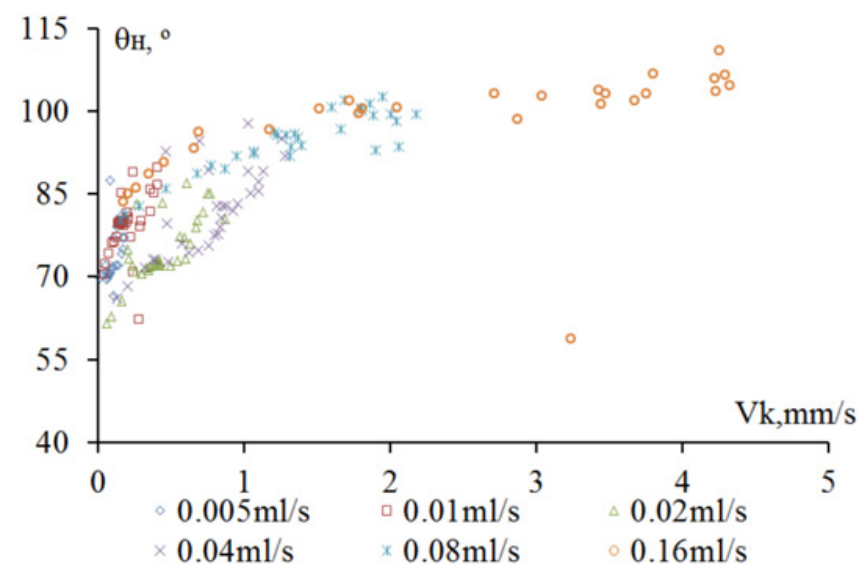

(b)

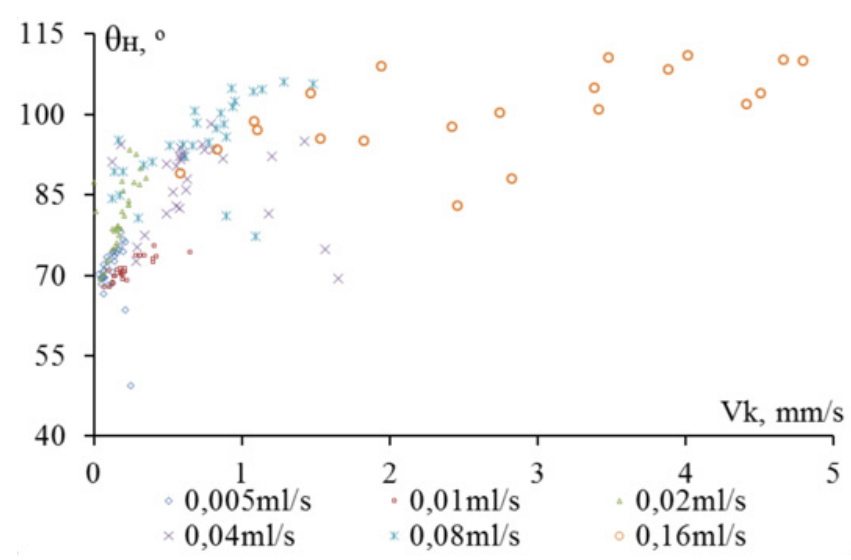

(c)

Figure 3. Dependence of advancing contact angle on velocity of movement of contact line at distilled water drop spreading on substrates made from: (a) flexible copper - Ra $0.591 \mu \mathrm{m}$; (b) copper II - Ra $5.190 \mu \mathrm{m}$; (c) copper III $-\operatorname{Ra} 6.210 \mu \mathrm{m}$. 
asperity. In our experiment roughness was formed by bombarding a surface with spherical particles of $\mathrm{Al}_{2} \mathrm{O}_{3}$. According [10] this method of making surface roughness is the most advanced, because agreeing with the author's conclusions just this form of micro roughness improves the hydrophobic properties of the surface.

Three regimes have been detected during drop spreading on the copper substrates. The first regime is characterized by "abrupt" increasing advancing DCA. There is a decrease in the advancing DCA at the second regime. In the third mode, the equilibrium contact angle is formed at a constant area of the wetted surface.

According to results of experiment it was found the difference in formation of the equilibrium contact angle at low and high rates of drop formation. At high rates of drop formation (0.020$0.160 \mathrm{ml} / \mathrm{sec}$ ) surface "defects" smoothed capillary waves on the surface of the liquid, contact line doesn't catch on the micro asperities and advancing DCA reduces during the spreading process. As a result increasing DCA when the process of spreading is over at low volume flow rate of distilled water drop formation $(0.005-0.010 \mathrm{ml} / \mathrm{sec})$ can be explained by contact line "catching" on the micro asperities of surface (pinning mode). This leads to an increase of DCA at the end of spreading, because driving force of the flow is not enough to overcome the micro asperities.

\section{Conclusion}

According to the results of experimental research static contact angles depending on volume flow rate have been measured for all used substrates. During the drop spreading on copper substrates effect of surface roughness on DCA has been obtained. There was an increase of DCA with increasing surface roughness. Perhaps the reason for the growth of DCA is that the contact angles affect not only surface roughness but also shape and arrangement of microgrooves and micro asperity.

Also it was found that DCA decreases at high rates of drop formation as three-phase contact line doesn't catch on the micro asperities. There was the contact line "catching" at low rates of drop formation and thus an increase of DCA.

The work was realized within the research state assignment "Science" (Code of Federal Target Scientific and Technical Program 2.1321.2014).

\section{References}

[1] J. Kim, Int J Heat Fluid Flow. 28, 753 (2007)

[2] D. Attinger, Z. Zhao, D. Poulikakos, Heat Mass Transfer 122, 544 (2000)

[3] P. Calvert, Chem. Mater. 13, 3299

[4] G. Li, S.M. Flores, C. Vavilala, et al. Langmuir 25, 13438 (2009)

[5] S.S. Sazhin, T. Kristyadi, W.A. Abdelghaffar and M.R. Heikal, Fuel 85, 1613 (2006)

[6] E.A. Chinnov, O.A. Kabov, Tech. Phys. Lett. 36, 468 (2010)

[7] E. Orlova, G. Kuznetsov and D. Feoktistov, EPJ Web of Conferences 76, 012039 (2014)

[8] O.A. Kabov, D.V. Zaitsev, Doklady Physics 451, 37 (2013)

[9] R.N. Wenzel, Ind. Eng. Chem. 28, 988 (1936)

[10] J.J. Foit, Nucl. Eng. Des. 227, 239 (2004) 